\title{
Bench-to-bedside review: Damage-associated molecular patterns in the onset of ventilator- induced lung injury
}

\author{
Maria T Kuipers ${ }^{1,2,3,4 *}$, Tom van der Poll3,4, Marcus J Schultz', ${ }^{1,2}$ and Catharina W Wieland ${ }^{1,2}$
}

\begin{abstract}
Mechanical ventilation (MV) has the potential to worsen pre-existing lung injury or even to initiate lung injury. Moreover, it is thought that injurious MV contributes to the overwhelming inflammatory response seen in patients with acute lung injury or acute respiratory distress syndrome. Ventilatorinduced lung injury (VILI) is characterized by increased endothelial and epithelial permeability and pulmonary inflammation, in which the innate immune system plays a key role. A growing body of evidence indicates that endogenous danger molecules, also termed damage-associated molecular patterns (DAMPs), are released upon tissue injury and modulate the inflammatory response. DAMPs activate pattern recognition receptors, may induce the release of proinflammatory cytokines and chemokines, and have been shown to initiate or propagate inflammation in non-infectious conditions. Experimental and clinical studies demonstrate the presence of DAMPs in bronchoalveolar lavage fluid in patients with VILI and the upregulation of pattern recognition receptors in lung tissue by MV. The objective of the present article is to review research in the area of DAMPs, their recognition by the innate immune system, their role in VILI, and the potential utility of blocking DAMP signaling pathways to reduce VILI in the critically ill.
\end{abstract}

\section{Introduction}

The oldest citations referring to artificial ventilation were found in Egyptian mythology: Isis resurrected Osiris with the breath of life [1]. The first documentation of positive pressure ventilation in humans dates from the 18th

*Correspondence: ilse.kuipers@amc.nl

'Laboratory of Experimental Intensive Care and Anesthesiology, Academic Medical Center, Meibergdreef 9, 1105 AZ Amsterdam, The Netherlands

Full list of author information is available at the end of the article century. Not much later, in the 19th century, the first questions concerning the safety of positive-pressure ventilation were raised [1]. Nowadays the use of mechanical ventilation (MV) is well established in intensive care medicine and is an essential tool in the management of patients with acute lung injury (ALI) or its more severe form, the acute respiratory distress syndrome (ARDS).

Both ALI and ARDS are devastating pulmonary conditions, and a high mortality rate persists despite advances in supportive care [2]. The exact pathogenesis of the uncontrolled inflammatory response seen in ARDS is not elucidated. A two-hit event has been postulated [3]: the first event being the underlying illness of the patient (for example, trauma or sepsis) and the second hit being injurious MV. However, injurious MV can both initiate lung damage and worsen pre-existing lung damage, termed ventilator-induced lung injury (VILI) in animals and ventilator-associated lung injury in humans [3-5]. The landmark study by the ARDS Network confirmed the clinical relevance of ventilator-associated lung injury by showing that the use of lower tidal volumes $\left(\mathrm{V}_{\mathrm{T}}\right)$ significantly reduced morbidity and mortality in ALI/ ARDS patients [4]. Lung-protective ventilator settings may limit but do not prevent pulmonary inflammation, however, and additional therapeutic strategies remain to be established.

The innate immune system plays a pivotal role in the initiation and progression of lung inflammation. This system offers the first line of defense against invading pathogens but it also recognizes the more recently discovered endogenous danger signals. These danger signals include intracellular molecules released after cell death or following immune cell activation and matrix degradation products, and are termed alarmins or damageassociated molecular patterns (DAMPs) [6,7]. DAMPs modulate inflammatory responses in infectious and noninfectious conditions to mediate tissue repair. However, DAMP signaling has also been linked to excessive inflammation associated with several inflammatory and autoimmune diseases. DAMPs activate pattern recognition receptors (PRRs) and trigger various signaling cascades 
involving the activation of the transcription factor NF- $\mathrm{kB}$, and subsequently the transcription of several proinflammatory genes [6]. The activation of NF- $\mathrm{kB}$ has previously been established in VILI [8]. In the past decade, numerous DAMPs have been identified and linked to inflammatory diseases [6]. Since DAMP-mediated inflammation involves activation of $\mathrm{NF}-\mathrm{kB}$, it can be postulated that DAMPs also play an essential role in VILI.

In the present review we focus on innate immune signaling in the lung triggered by DAMPs. We discuss both experimental and clinical studies highlighting the role of DAMPs and PRRs in lung injury and VILI. We also speculate on the potential clinical utility of blocking DAMP signaling pathways in VILI.

\section{Ventilator-induced lung injury and the danger model} Distinct injury mechanisms contribute to VILI development. Computerized tomography visualized that lung inflation in ALI is heterogeneous [9]. Injured regions are fluid filled or collapsed, while healthy regions remain well aerated and are at risk for overdistension. Repetitive opening and closure of collapsed lung parts induces shear forces acting on pulmonary cells causing atelectrauma [10]. In the absence of gross structural lung damage, however, pulmonary stretch can still alter cellular metabolism, change gene expression, and induce the release of inflammatory cytokines and chemokines. MV-induced molecular and cell-mediated events are termed biotrauma [11].

In the presence of pre-existing pulmonary abnormalities, the susceptibility of lungs to MV is increased. Hernandez and colleagues published one of the first papers that demonstrated this synergistic interaction. Oleic acid administration or MV individually had minimal effects on lung capillary filtration coefficients in isolated perfused rabbit lungs [12]. However, the combination of oleic acid injury with MV significantly increased microvascular permeability. Other investigators observed synergistic interactions between $\mathrm{MV}$ and intravenously or intrapulmonary microbial cell wall products such as lipopolysaccharide (LPS) $[13,14]$. Similarly, the combination of pulmonary infection and MV was more deleterious to the lung (increased influx of neutrophils, augmented production of proinflammatory cytokines, and increased barrier dysfunction) than either one alone [15].

Indeed, lungs with pre-existing abnormalities possess a smaller number of healthy alveoli and are more at risk for injury due to regional increased mechanical forces. In addition, increased levels of proinflammatory mediators and DAMPs are present during inflammation and may prime the inflammatory response. Cellular injury and plasma membrane wounding due to injurious MV may further increase DAMP tissue levels, which in turn aggravates the proinflammatory cascade. Moreover, it is thought that the presence of pathogens and DAMPs might amplify each other both at the receptor level and in the activation of transcriptional factors [6].

For over 50 years it was believed that our immune system merely distinguishes between self and nonself. Recently, the danger model was introduced - a viewpoint that outlines the immune response to tissue injury [7]. This theory describes the immune activation by endogenous danger signals and states that immunity is more concerned with injury than with foreignness. The introduction of the danger model stimulated the search for DAMPs and their signaling pathways. Before we discuss DAMP signaling in VILI we provide a brief overview of PRRs and DAMPs.

\section{Pattern recognition receptors and DAMP signaling}

There is a wide range of innate immune sensors known as PRRs. These are critical in host response by recognizing pathogen-associated molecular patterns (PAMPs) but they are also activated by DAMPs. Toll-like receptors (TLRs) represent the best-known class. Other DAMP receptors are nucleotide-binding oligomerization domainlike receptors (NLRs) and the receptor for advanced glycation end products (RAGE).

\section{Toll-like receptors}

TLRs are expressed by a range of immune cells including dendritic cells, macrophages and B cells, but also by nonimmune cells including epithelial cells [16]. All TLRs, except for TLR3, recruit myeloid-differentiation primary response protein 88 (MyD88) as an adaptor protein, crucial for the activation of NF- $\mathrm{kB}$, which controls the expression of proinflammatory mediators [16]. In TLR4 and TLR3 signaling, a second downstream pathway is involved. This pathway is mediated by Toll/IL- 1 receptor domain-containing adaptor-inducing IFN- $\beta$ (TRIF) protein and results in delayed NF- $\mathrm{kB}$ activation and activation of type I interferons [16].

\section{Toll-like receptor activating DAMPs}

Hyaluronan (HA) is part of the extracellular matrix and its high molecular weight (HMW) form is an important molecule in tissue architecture. Low molecular weight (LMW) HA is synthesized under inflammatory conditions by hyaluronan synthase-3 (HAS3) or is formed by the breakdown of HMW HA. LMW HA accumulates at sites of inflammation and stimulates macrophages to produce chemokines via TLR2 and TLR4 activation [17]. Biglycan is a small leucin-rich proteoglycan, which is another constituent of the extracellular matrix. During tissue injury or by excretion from activated macrophages, biglycan becomes available in its soluble form and increases TNF $\alpha$ and macrophage inflammatory protein-2 (MIP2) levels via TLR2 and TLR4 [18]. Other extracellular matrix components such as versican, heparan 
sulfate, fibronectin, and tenascin-C can also activate TLR2 and/or TLR4 [19].

The heat shock proteins (HSPs) are molecular chaperones abundantly present in the cytosol. Increased expression of HSPs is induced in response to a wide variety of insults, including heat stress. Intracellular HSPs have antiapoptotic properties, and extracellular HSPs interact with the immune system via TLR2 and TLR4 [20]. Caution is warranted when interpreting HSP data: LPS contamination of the HSP preparations used in studies is a well-known problem.

High-mobility box group-1 (HMGB1) is a nuclear chromatin-associated protein and an important mediator in sterile inflammation when released in the extracellular space [21]. It is passively released from necrotic cells, but HMGB1 can also be actively secreted by several immune cells 8 to 12 hours after TLR ligation [21]. TLR4-HMGB1 interactions activate the MyD88 pathway and are important for macrophage activation and cytokine release. Although there is debate whether highly purified HMGB1 can directly activate cells, it is now accepted that other molecules bound by HMGB1, at least in part, are responsible for the detrimental effects of extracellular HMGB1.

The S100 family of proteins, or calgranulins, consists of more than 20 intracellular calcium-binding proteins implicated in cell homeostasis and regulation of the cytoskeleton [22]. S100A8 and S100A9 form heterodimers, their physiologically relevant form, and are secreted by activated phagocytes during inflammation. Extracellular S100A8/A9 activates endothelial cells, and murine S100A8 has been shown to induce chemotaxis in vitro [22]. S100A8/A9 proteins are ligands for TLR4 [23]. $\beta$-defensins are host-derived antimicrobial peptides and signal via TLR4 and TLR1/2 [24,25].

In cellular injury, nucleic acids are released. Mammalian mRNA can activate TLR3, leading to IFN $\alpha$ secretion [26]. Single-stranded RNA is sensed by TLR7 and TLR8 [27]. Mitochondria might carry bacterial molecular patterns, being evolutionary endosymbionts derived from bacteria. Mitochondrial DNA can activate TLR9 and stimulate neutrophil migration and degranulation [28].

Fatty acids and lipoproteins such as serum amyloid A, oxidized low-density lipoprotein and saturated fatty acids can activate TLR2 and TLR4 [19]. A more detailed list of all endogenous TLR activators has been previously published [19], and a schematic overview of DAMPs and TLR signaling pathways can be found in Figure 1.

\section{Nucleotide-binding oligomerization domain-like receptors} Intracellular sensors of infection and tissue injury have been recently identified and termed NLRs [29]. The NLR family consists of more than 20 members, but in the present review we focus on the function of NLRP3 (or NALP3 or cryoporin) in DAMP signaling.
NLRP3, expressed by immune cells, epithelial cells, and osteoblasts, assembles with adaptor protein ASC (apoptosis-associated speck-like protein) and caspase-1 to form a multiprotein complex termed the NLRP3 inflammasome [29]. NLRP3 inflammasome-dependent caspase-1 activation leads to maturation and release of IL- $1 \beta$ and IL-18. A two-step process is required for NLRP3 inflammasome signaling: a priming step (signal 1) and a NLRP3 activation step (signal 2). Signal 1 induces NF- $k B$ dependent production of pro-IL-1 $\beta$ and pro-IL-18 via, for example, activation of TLRs. Signal 2 can be provided by the presence of PAMPs, inhaled large particles, and DAMPs. How these various stimuli are recognized by NLRP3 and trigger NLRP3 activation is still not completely elucidated. Potassium efflux, production of reactive oxygen species, and lysosomal damage with cathepsin $B$ release are intracellular features associated with NLRP3 activation [30].

\section{NLRP3 inflammasome-activating DAMPs}

Intracellular ATP is a nucleotide with a primary function in energy metabolism. Extracellular ATP has a function in cell communication and its release from healthy cells is tightly regulated [31]. Cell damage and/or cellular stress leads to an uncontrolled release of ATP. The ATP-induced NLRP3 inflammasome activation requires activation of the $\mathrm{P} 2 \mathrm{X}_{7}$ receptor in combination with the pannexin-1 channel and decreases intracellular potassium levels $[29,32]$.

Another NLRP3-activating DAMP is uric acid, the main metabolite of the cellular catabolism of purines that at high local concentrations precipitates and forms crystals [33]. Phagocytosis of uric acid crystals can induce lysosomal damage and the release of cathepsin B [33]. Uric acid crystals may also trigger potassium efflux and/or induce reactive oxygen species production.

Extracellular matrix components HA and biglycan have also been shown to induce NLRP3 activation [34,35]. The association of HA with CD44 and the mechanism of HA catabolism, such as endocytosis and lysosmal hyaluronidase activity, are needed to trigger intracellular NLRP3 [34]. How these small intracellular saccharides activate NLRP3 is still unclear. Biglycan can interact with multiple receptors, including the $\mathrm{P}_{2} \mathrm{X}_{7}$ receptor, in order to form multireceptor complexes [35]. Furthermore, biglycan induces the formation of reactive oxygen species.

A schematic overview of NLRP3 inflammasome signaling can be found in Figure 2 .

\section{Receptor for advanced glycation end products}

RAGE is a multiligand receptor that is highly expressed in lung tissue, primarily by type I alveolar cells $[36,37]$. The RAGE receptor contains one V-domain and two Cdomains extracellularly. The receptor has a transmembrane 


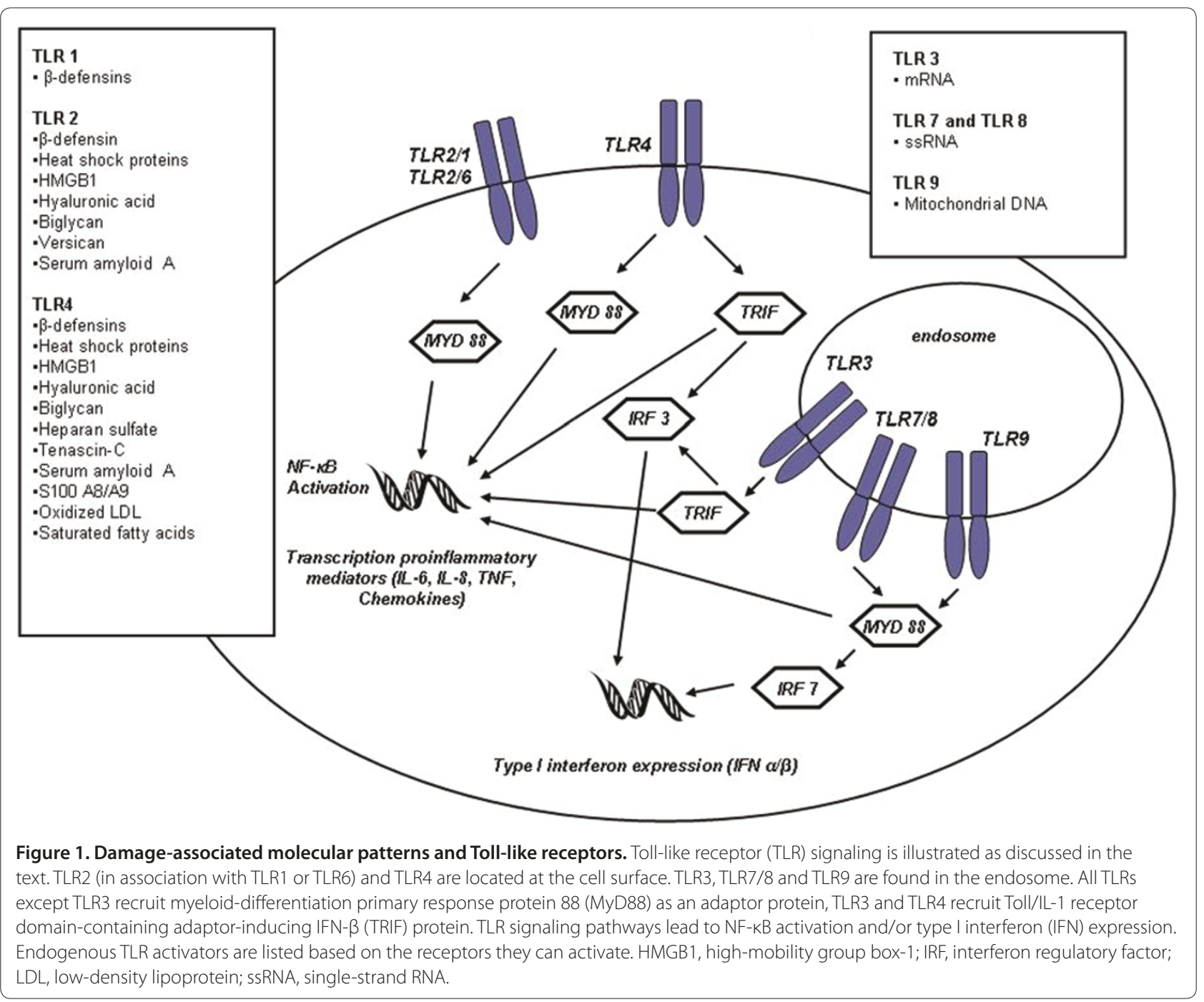

part and a cytoplasmic tail, which is important for intracellular signaling. Although the exact downstream signaling after RAGE-ligand interaction is largely unknown, it ultimately leads to the activation of the NF- $\mathrm{kB}$ and mitogen-activated protein kinase signaling pathways [36]. Soluble RAGE, a RAGE isoform lacking the transmembrane domain, can be used as a marker of alveolar epithelial type I cell injury [37]. Furthermore, it is thought that soluble RAGE can act as a decoy receptor by competing with full-length RAGE for ligand binding $[36,37]$.

\section{RAGE-activating DAMPs}

RAGE interacts with various ligands. S100A12, also a member of the $\mathrm{S} 100$ family of proteins, is mainly found in granulocytes, and contributes to endothelial and leukocyte activation via binding with RAGE [22]. HMGB1RAGE interactions stimulate chemotaxis, immune cell differentiation and migration, cell growth, and the upregulation of receptors such as TLR4 and RAGE [21]. Other known RAGE ligands are amyloid, $\beta$-sheet fibrils, S100B, and S100P [36].

\section{DAMPs in ventilator-induced lung injury}

Whether MV results in the release of DAMPs and, if so, which ventilator settings are responsible were key questions tackled by investigators in the past decade. In addition, laboratory studies investigated whether DAMPs indeed enhance VILI and explored DAMP scavenging strategies.

\section{Hyaluronan}

Previously it was shown that HA levels in bronchoalveolar lavage fluid (BALF) were six times higher in ARDS patients compared with control patients [38]. The role of HA in VILI was first studied in vitro [39]. Cyclic stretch 


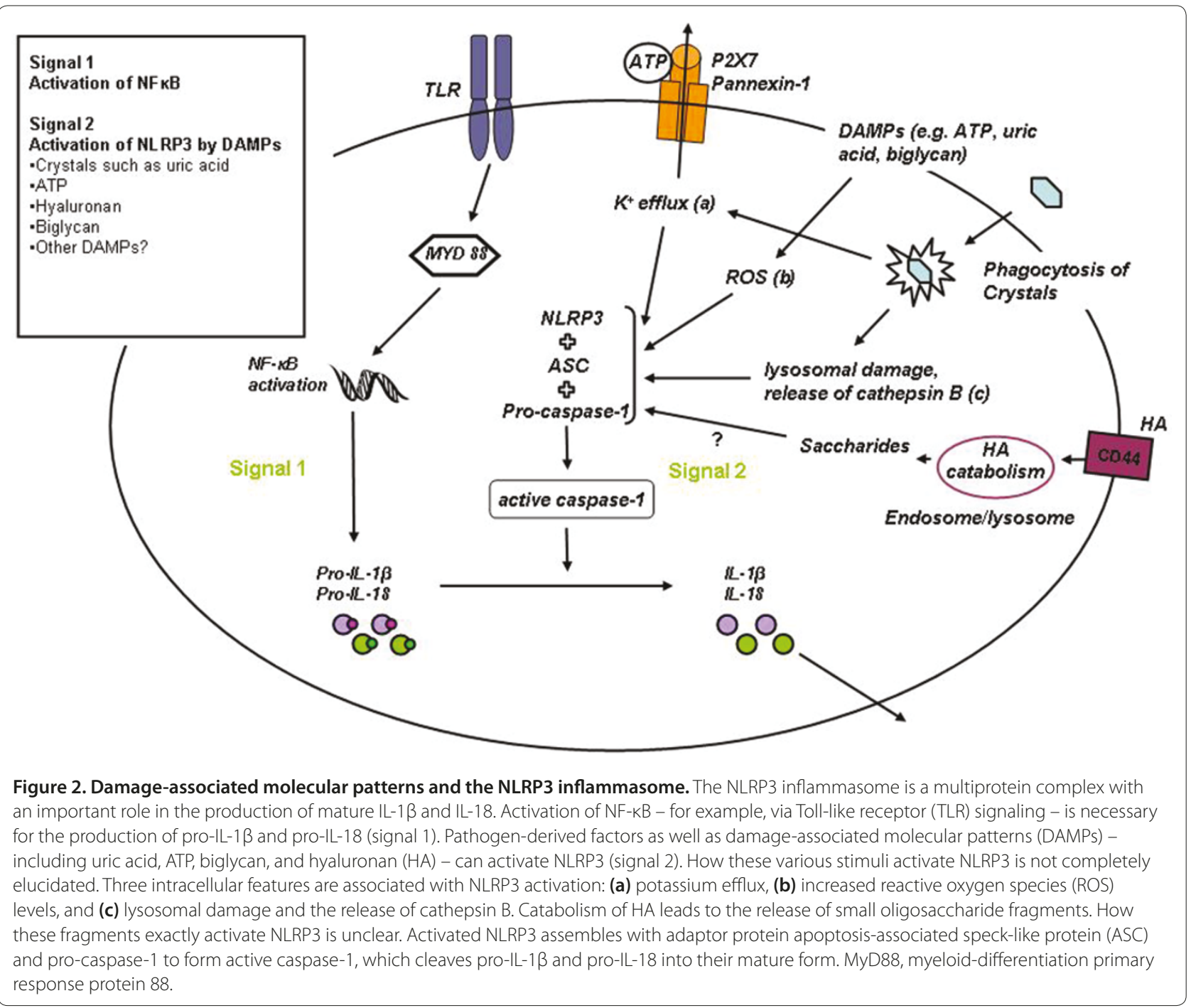

of human fibroblasts triggered the release of soluble LMW HA. Furthermore, stretch-induced LMW HA was able to increase the production of IL- 8 in both static and stretched epithelial cells [39]. Other investigators observed that LMW HA can induce epithelial-to-mesenchymal transition in alveolar type II cells via the MyD88 pathway [40]. When injured, alveolar type II cells are capable of self-renewal but can also undergo epithelial-to-mesenchymal transition, which may contribute to the development of lung fibrosis and subsequently respiratory failure.

Mice ventilated for 5 hours with high $\mathrm{V}_{\mathrm{T}}(30 \mathrm{ml} / \mathrm{kg})$ were found to have increased LMW HA and HAS3 mRNA levels in lung tissue [41]. Ventilated HAS3 knockout (KO) mice had significantly reduced LMW HA levels, neutrophil infiltration, and MIP2 (rodent equivalent for human IL-8) production compared with ventilated wild-type mice [41]. In search for a treatment strategy that would reduce LMW HA levels produced by
HAS3, phosphodiesterase-3 inhibitors were studied [42]. Treatment of septic ventilated rats resulted in decreased HAS3 expression levels in lung tissue. Moreover, alveolar protein levels, neutrophil influx, and lung injury scores were reduced. Whether these anti-inflammatory properties are indeed all mediated by inhibition of HAS3 and a reduction of LWM HA levels remains to be elucidated.

Conversely, HMW HA exerts anti-inflammatory and anti-apoptotic effects $[17,43]$. Transgenic mice that overexpress HMW HA are protected from bleomycininduced lung injury [17]. Furthermore, HMW HA pretreatment inhibited inflammatory cell infiltration, cytokine production and the extent of lung injury in a rat model of sepsis combined with mechanical ventilation [43]. It is thought that the beneficial effects of HMW HA are secondary to an altering in the balance of HA in favor of the HMW form, thereby maintaining the integrity of the extracellular matrix. 


\section{Other extracellular matrix components}

Injurious $\mathrm{MV}$ ( 2 hours, $\mathrm{V}_{\mathrm{T}}=30 \mathrm{ml} / \mathrm{kg}$ ) resulted in elevated lung levels of versican, heparan sulfate proteoglycan and biglycan compared with non-injurious ventilated rats ( 2 hours, $\mathrm{V}_{\mathrm{T}}=8 \mathrm{ml} / \mathrm{kg}$ ) [44]. The dynamic alterations of extracellular matrix components during VILI can influence viscoelastic properties of the lung but may also contribute to the progression of pulmonary inflammation. Further studies are warranted.

\section{Heat shock proteins}

Induction of HSPs mediates cellular protection against harmful stimuli. Kira and colleagues documented the upregulation of pulmonary HSP70 expression due to injurious MV (30 minutes, positive inspiratory pressure with $30 \mathrm{cmH}_{2} \mathrm{O}$ ) in rats [45]. Induction of HSP70 suppressed cytokine-induced IL-8 and TNF $\alpha$ expression in respiratory epithelial cells [46]. HSP induction was shown to stabilize inhibitory $\mathrm{kB}$ factor, indicating attenuated NF- $\kappa B$ activation [46]. In line with this, Ribeiro and colleagues observed lower levels of proinflammatory cytokines and a better lung compliance in ex vivo rat lungs pretreated with heat stress 18 hours before the start of injurious MV (2 hours, $\mathrm{V}_{\mathrm{T}}=40 \mathrm{ml} / \mathrm{kg}$ ) [47]. However, timing is essential for the cytoprotective effects of the heat shock response. Induction of HSPs in cells already primed by inflammation might lead to cell death by apoptosis [48].

More recently, the role of extracellular HSPs has become an area of interest. Presence of extracellular HSP72 was reported in BALF and plasma of ALI patients [49]. In vitro, extracellular HSP72 induced a dose-dependent increase in IL-8 expression and activation of NF- $\mathrm{kB}$ in bronchial epithelial cells [50]. Moreover, intratracheal installation of HSP72 in mice induced upregulation of keratinocyte-derived chemokine and TNF $\alpha$ levels, and increased neutrophil influx in BALF [50]. TLR4 mutant mice did not develop a similar inflammatory response to intratracheal HSP72, stressing the important role of TLR4 in HSP-mediated inflammation. Further research is needed to understand the divergent response to HSPs. Strategies that activate HSP genes may be beneficial in the pathogenesis of VILI, and antibodies that block extracellular HSP could reduce pulmonary inflammation.

\section{High-mobility box group-1}

A rise in HMGB1 levels in response to MV has been observed [51,52]. HMGB1 concentrations in the BALF of patients subjected to long-term ventilator therapy $\left(\mathrm{V}_{\mathrm{T}}\right.$ $<8 \mathrm{ml} / \mathrm{kg}$ and optimal positive end-expiratory pressure) were increased when compared with a control group of healthy volunteers [51]. In an in vivo VILI model, levels of HMGB1 in BALF were fivefold higher in the high $V_{T}$ group (4 hours, $V_{T}=30 \mathrm{ml} / \mathrm{kg}$ ) when compared with the lower $\mathrm{V}_{\mathrm{T}}$ group $\left(\mathrm{V}_{\mathrm{T}}=8 \mathrm{ml} / \mathrm{kg}\right)$ [52]. Blocking HMGB1 led to a significant reduction in neutrophil influx and TNF $\alpha$ concentration in BALF, improved oxygenation, and limited microvascular permeability [52]. These results indicate that the presence of enhanced HMGB1 levels exerts detrimental effects in the lung. In line with this hypothesis, Abraham and colleagues observed pulmonary neutrophil accumulation, lung edema, and increased production of IL-1 $\beta$, TNF $\alpha$, and MIP2 due to intratracheal administration of HMGB1 in mice [53]. Numerous experimental disease models (including sepsis, ischemia-reperfusion injury and arthritis) responded to therapy targeting HMGB1, which might indicate that removing or neutralizing HMGB1 attenuates innate immune system activation and reduces tissue damage [21]. HMGB1 is a promising target for future therapy. Careful patient selection will be necessary, however, since antibodies may also interfere with beneficial qualities of HMGB1 such as potential antitumor activities [21].

\section{S100 proteins}

S100A9 mRNA is upregulated in rat lungs undergoing injurious MV (30 minutes, $\mathrm{V}_{\mathrm{T}}=25 \mathrm{ml} / \mathrm{kg}$ ) [54]. In mice, 4 hours of $\mathrm{MV}$ with a conventional $\mathrm{V}_{\mathrm{T}}$ of 10 to $12 \mathrm{ml} / \mathrm{kg}$ also enhanced the pulmonary transcription of S100A9 mRNA [14]. Both studies used whole lung tissue as the source of mRNA, making the interpretation of which cells are responsible for the changes in gene expressions difficult. The expression of S100A12 in lung tissue and the concentration of S100A12 in BALF were both significantly higher in patients with ARDS when compared with healthy controls [55,56]. In addition, S100A8/A9 protein levels were elevated in the BALF of ARDS patients relative to healthy controls [56]. Although studies revealed the presence of S100 proteins in the inflamed lung, the role of these proteins has not been studied extensively. Their shown potential to activate leukocytes and endothelial cells warrants further research.

\section{Adenosine 5'-triphosphate}

Animal studies demonstrated increased ATP concentrations in BALF due to injurious MV (30 minutes, positive inspiratory pressure $40 \mathrm{cmH}_{2} \mathrm{O}$ and 1 hour, $\mathrm{V}_{\mathrm{T}}=40 \mathrm{ml} / \mathrm{kg}$ ) $[57,58]$. To determine whether extracellular ATP contributed to VILI development, ATP was administered before the onset of low-pressure ventilation (30 minutes, positive inspiratory pressure $15 \mathrm{cmH}_{2} \mathrm{O}$ ). Intratracheal ATP significantly increased the volume of epithelial lining fluid during low-pressure MV [57]. In line with this, other investigators studied the effects of intratracheal ATP in nonventilated mice [58]. ATP increased the pulmonary wet to dry ratio, the lung permeability index and mRNA expression of IL-6, TNF- $\alpha$, and MIP2, and induced aggregation of inflammatory cells in alveolar 
tissue. ATP signals via P2 purinergic receptors and blockage with a specific P2 receptor antagonist, just before the onset of MV, partially mitigated the inflammatory response during high tidal ventilation [58]. Recently, elevated pulmonary ATP concentrations were observed in patients with lung fibrosis and mice with bleomycin-induced lung injury [59]. In mice, ATP levels were reduced using an ATP-degrading enzyme - this resulted in attenuated inflammatory cell recruitment, lung IL-1 $\beta$ levels and matrix remodeling protein tissue inhibitor of metalloproteinase-1 concentrations. ATPinduced inflammation was mediated by the ATP/P2X axis. Whether this axis also contributes to VILI development remains an interesting topic for future studies.

\section{Uric acid}

Injurious MV (5 hours, $\mathrm{V}_{\mathrm{T}}=15 \mathrm{ml} / \mathrm{kg}$ ) increased uric acid levels in BALF of mice [60]. When mice were pretreated with allopurinol (uric acid synthesis inhibitor) or uricase (degrades uric acid), alveolar barrier dysfunction was attenuated [60]. Gasse and colleagues demonstrated pulmonary uric acid accumulation in a bleomycin-induced lung injury model [61]. Local administration of uric acid crystals induced dosedependent cell recruitment in BALF, IL-1 $\beta$ production and tissue inhibitor of metalloproteinase- 1 expression, establishing uric acid as a major endogenous danger signal. Uric-acid-induced lung inflammation was mediated by the NLRP3 inflammasome, MyD88, and the IL-1 receptor 1 pathway and the combined action of TLR2 and TLR4 for optimal inflammation [61].

\section{Pattern recognition receptors in ventilator-induced lung injury}

Toll-like receptors in ventilator-induced lung injury

After 4 hours of low tidal MV $\left(\mathrm{V}_{\mathrm{T}}=8 \mathrm{ml} / \mathrm{kg}\right)$, TLR4 $\mathrm{KO}$ mice displayed lower pulmonary cytokine and chemokine levels compared with ventilated wild-type animals [62]. Moreover, MV caused release of endogenous TLR4 ligands in BALF [62]. In line with this, lower pulmonary IL-1 $\beta$ and keratinocyte-derived cytokine levels and NF- $\mathrm{kB}$ activity were observed in similarly ventilated TRIF KO mice [63]. The TLR4-TRIF pathway was therefore suggested as a dominant signaling cascade involved in MV-induced inflammation [62]. However, a role for TLR3 signaling cannot be excluded.

Chun and colleagues studied TLR involvement in VILI using a model in which MV (6 hours, $\mathrm{V}_{\mathrm{T}}=10 \mathrm{ml} / \mathrm{kg}$ ) was combined with TLR3-mediated lung inflammation [64]. Interestingly, they demonstrated that MV-associated augmentation of TLR3-induced lung inflammation occurred via the MyD88 pathway. Since TLR4 signals via MyD88, their next step was to identify the role of TLR4 in this model. In contrast to Vaneker and colleagues' study [62], TLR4 KO mice displayed no significant differences in cytokine concentrations, neutrophil influx or lung permeability when compared with wild-type mice [64]. These results suggest that other MyD88-dependent receptors are required for MV augmentation of TLR3induced lung inflammation - the TLR4-MyD88 pathway, however, seems not to be involved. The use of a TLR3 agonist makes it difficult to separate out the effect of MV on TLR4-TRIF activation, since a part of this signaling cascade is already activated by the TLR3 agonist. In isolated perfused lungs of $\mathrm{C} 3 \mathrm{H} / \mathrm{HeJ}$ mice, which lack functional TLR4, injurious MV (3.5 hours, $\mathrm{V}_{\mathrm{T}}=15 \mathrm{ml} / \mathrm{kg}$ ) still resulted in NF- $\mathrm{BB}$ activation [8]. These results suggest that other PRRs may contribute to MV-induced inflammation.

The exact role of TLR2 in VILI is a matter of debate. Although TLR2 mRNA expression levels in lung tissue of healthy mice increased due to $\mathrm{MV}$ (4 hours, $\mathrm{V}_{\mathrm{T}}=$ $8 \mathrm{ml} / \mathrm{kg}$ ), lungs from TLR2 KO mice did not show attenuated cytokine levels [62]. In contrast to the findings in the mouse model, a more recent study conducted in rats demonstrated that TLR4 mRNA, but not TLR2 mRNA, was upregulated by injurious MV (4 hours, $\mathrm{V}_{\mathrm{T}}=$ $15 \mathrm{ml} / \mathrm{kg}$ ) [65]. TLR3 expression is enhanced in lung histological slides of ARDS patients [66]. Although not studied in VILI, TLR3 KO mice were protected from hyperoxia-induced ALI [66]. The negative regulator of MyD88-dependent TLR signaling, IL-1-receptor-associated kinase-M (IRAK-M), is a possible regulator of VILI [65]. In the absence of infection, IRAK-M was downregulated by injurious MV (4 hours, $\mathrm{V}_{\mathrm{T}}=15 \mathrm{ml} / \mathrm{kg}$ ).

TLR signaling pathways that are activated in response to pathogens are modulated by MV. In septic rats (induced by cecal ligation and puncture), injurious MV ( 4 hours, $\mathrm{V}_{\mathrm{T}}=20 \mathrm{ml} / \mathrm{kg}$ ) influenced TLR4 and IRAK-M protein levels, pulmonary and systemic cytokines, and mortality [67]. CD14, an important accessory protein for LPS-TLR4 ligand interaction, was upregulated due to 4 hours of injurious $\mathrm{MV}\left(\mathrm{V}_{\mathrm{T}}=20 \mathrm{ml} / \mathrm{kg}\right)$ in rabbits [68]. In addition, alveolar macrophages from these ventilated animals were stimulated with LPS: TNF $\alpha$ release in the injurious MV group was 20-fold higher than in the low $\mathrm{V}_{\mathrm{T}}$ group $(5 \mathrm{ml} / \mathrm{kg})$. These results suggest that mechanical stress can sensitize lungs to endotoxin, partially via CD14 upregulation [68].

Up to now, many studies have been conducted to unravel the role of TLRs, TLR ligands, and their specific signaling pathways. However, there are still many questions to be answered. Whether TLR4 plays an important role in VILI is uncertain but is of potential interest as TLR4 antagonists are available for use in humans.

\section{NLRP3 inflammasome in ventilator-induced lung injury}

Preclinical and clinical studies previously demonstrated an important role for IL-1 $\beta$, the main product of 
activated NLRP3 inflammasome, in the pathogenesis of VILI [69,70]. IL-1 receptor KO mice displayed less alveolar barrier dysfunction due to injurious MV (3 hours, $\mathrm{V}_{\mathrm{T}}=30 \mathrm{ml} / \mathrm{kg}$ ) when compared with wild-type mice [70].

The role of NLRP3 inflammasome in VILI has not been studied. Recently, NLRP3 signaling in a bleomycininduced lung injury model was established. NLRP3 and ASC KO mice, both unable to assemble the NLRP3 inflammasome, displayed less lung inflammation compared with wild-type mice [61]. Given the presence of NLRP3 ligands ATP and uric acid in VILI and the proven role of IL-1 $\beta$, we expect there is a role for NLRP3 in VILI.

\section{RAGE in ventilator-induced lung injury}

Soluble RAGE levels are significantly higher in pulmonary edema fluid and plasma from ALI/ARDS patients compared with patients with hydrostatic edema [37]. Soluble RAGE concentrations are also elevated in BALF from rats with LPS or hydrochloric acid-induced ALI [37]. In mice with LPS-induced lung injury, soluble RAGE treatment attenuated neutrophil influx, lung permeability, pathological lung changes, and NF- $\kappa B$ activity [71].

RAGE is highly expressed in lung tissue and might have a role in cell physiology of healthy lungs. Spontaneous development of pulmonary fibrosis-like alterations in aged RAGE KO mice has been demonstrated [72]. However, lack of RAGE in younger mice with bleomycin or hyperoxia-induced lung injury resulted in reduced lung inflammation [73,74]. We speculate that RAGE signaling also exerts detrimental effects in VILI, but future studies are mandatory to elucidate the exact role of RAGE.

\section{Future perspective on blocking DAMP signaling pathways}

Increasing the knowledge of the innate immune response in MV-induced inflammation may lead to treatment options in which DAMPs or their signaling pathways can serve as possible therapeutic targets. DAMP-mediated inflammation is a double-edged sword: low levels may play a pivotal role in tissue repair and protection of the host, whereas high levels may trigger further tissue injury and DAMP release, leading to a chronic inflammatory state.

To maintain the balance, DAMPs are counteracted by natural inhibiting molecules: uric acid levels are reduced by uricase, and soluble RAGE may dampen HMGB1induced inflammation. HMGB1 autoantibodies were recently shown to be produced during sepsis [75]. Interestingly, increased levels of these autoantibodies were associated with a better outcome in patients with septic shock [75].
Modulating TLR activity is a possible approach to temper excessive inflammation. Current approaches target individual TLRs with antibodies, soluble receptors, natural antagonists and small molecule inhibitors, block downstream TLR signaling pathways, or use PAMP analogues for TLRs [21]. An example of this last category of approach is eritoran tetrasodium, a structural analogue of the lipid A portion of LPS that blocks TLR4 signaling [76]. The exact role of eritoran tetrasodium in blocking the inflammatory response in severe sepsis has been the subject of investigation in a phase III study: the results await publication. We have to keep in mind that modulating PRRs may be beneficial in inflammatory disease but their activity is vital in order to survive infection. Targeting endogenous danger signals is likely to be safer. Blockade of DAMPs in VILI has therapeutic potential in animal models. Allopurinol and/or uricase, both already established therapies for hyperuricemia during the tumor lysis syndrome or gout, have shown to be an attractive strategy in lung injury [60,61]. Use of HMGB1 antibodies in a VILI model improved oxygenation and reduced neutrophil influx and cytokine production [52].

There are many different DAMPs released in inflammation, and perhaps we need to target more than one to reduce severe inflammation. The relative contribution of these DAMPs may differ between various tissues and identifying candidate molecules with the highest impact in VILI would be an interesting topic for future research.

Studies in humans demonstrate an enormous variability in the inflammatory response towards microbial products. Indeed, susceptibility and immune responses are in part heritable. It is likely that these individual genetic variations also influence the inflammatory response towards DAMPs. Markers of high genetic susceptibility to identify high-risk patients for developing severe lung injury might be of great value for future therapies.

Although PAMPs and DAMPs can activate the same receptors, increasing evidence suggest that they may use differential binding sites or need differential co-receptors and accessory molecules for receptor activation [19]. Moreover, it is thought they may use distinct downstream signaling pathways and initiate different biological outcomes. Further detailed research is necessary to elucidate the exact molecular mechanisms of DAMP receptor activation and signaling during VILI. This knowledge may lead to future treatment options targeting overwhelming DAMP inflammation without compromising the host defense against invading pathogens.

\section{Conclusions}

Several DAMPs and their potential to evoke sterile inflammation have been characterized in the past decade. 
Although studies demonstrated the importance of DAMP signaling in MV-induced inflammation, extensive research is imperative for the identification of all DAMPs released in VILI and for the therapeutic relevance of selectively targeting DAMP release, DAMP receptors or downstream signaling pathways to attenuate VILI.

\section{Abbreviations}

ALI, acute lung injury; ARDS, acute respiratory distress syndrome; ASC, apoptosis-associated speck-like protein; BALF, bronchoalveolar lavage fluid; DAMP, damage-associated molecular pattern; HA, hyaluronan; HAS3, hyaluronan synthase 3; HMGB1, high-mobility group box-1; HMW, high molecular weight; HSP, heat shock protein; IFN, interferon; IL, interleukin; IRAK-M, IL-1-receptor-associated kinase-M; KO, knockout; LMW, low molecular weight; LPS, lipopolysaccharide; MIP2, macrophage inflammatory protein-2; MV, mechanical ventilation; MyD88, myeloid-differentiation primary response protein 88; NF-KB, nuclear factor kappa B; NLR, nucleotide-binding oligomerization domain-like receptor; PAMP, pathogen-associated molecular pattern; PRR, pattern recognition receptor; RAGE, receptor for advanced glycation end products; TLR, Toll-like receptor; TNF, tumor necrosis factor; TRIF Toll/IL-1 receptor domain-containing adaptor-inducing IFN- $\beta$; VILI, ventilatorinduced lung injury; $V_{T}$, tidal volume.

\section{Competing interests}

The authors declare that they have no competing interests.

\section{Acknowledgements}

CWW was sponsored by the Dutch Organization of Scientific Research (NWO).

\section{Author details}

'Laboratory of Experimental Intensive Care and Anesthesiology, Academic Medical Center, Meibergdreef 9, 1105 AZ Amsterdam, The Netherlands. Department of Intensive Care, Academic Medical Center, Meibergdreef 9, 1105 AZ Amsterdam, The Netherlands. ${ }^{3}$ Center of Experimental and Molecular Medicine, Academic Medical Center, Meibergdreef 9, 1105 AZ Amsterdam, The Netherlands. ${ }^{4}$ Center of Infection and Immunity, Academic Medical Center, Meibergdreef 9, 1105 AZ Amsterdam, The Netherlands.

Published: 30 November 2011

\section{References}

1. Baker AB: Artificial respiration, the history of an idea. Med Hist 1971, 15:336-351

2. Brun-Buisson C, Minelli C, Bertolini G, Brazzi L, Pimentel J, Lewandowski K, Bion J, Romand JA, Villar J, Thorsteinsson A, Damas P, Armaganidis A, Lemaire F; ALIVE Study Group: Epidemiology and outcome of acute lung injury in European intensive care units. Results from the ALIVE study. Intensive Care Med 2004, 30:51-61.

3. Tremblay LN, Slutsky AS: Ventilator-induced lung injury: from the bench to the bedside. Intensive Care Med 2006, 32:24-33.

4. Acute Respiratory Distress Syndrome Network: Ventilation with lower tidal volumes as compared with traditional tidal volumes for acute lung injury and the acute respiratory distress syndrome. N Engl J Med 2000, 342:1301-1308

5. Determann RM, Royakkers A, Wolthuis EK, Vlaar AP, Choi G, Paulus F, Hofstra JJ, de Graaff MJ, Korevaar JC, Schultz MJ: Ventilation with lower tidal volumes as compared with conventional tidal volumes for patients without acute lung injury: a preventive randomized controlled trial. Crit Care 2010, 14:R1

6. Bianchi ME: DAMPs, PAMPs and alarmins: all we need to know about danger. J Leukoc Bio/ 2007, 81:1-5.

7. Matzinger P: The danger model: a renewed sense of self. Science 2002, 296:301-305.

8. Held HD, Boettcher S, Hamann L, Uhlig S: Ventilation-induced chemokine and cytokine release is associated with activation of nuclear factor- $\mathrm{KB}$ and is blocked by steroids. Am J Respir Crit Care Med 2001, 163:711-716.

9. Gattinoni L, Pesenti A, Avalli L, Rossi F, Bombino M: Pressure-volume curve of total respiratory system in acute respiratory failure. Computed tomographic scan study. Am Rev Respir Dis 1987, 136:730-736.

10. Muscedere JG, Mullen JB, Gan K, Slutsky AS: Tidal ventilation at low airway pressures can augment lung injury. Am J Respir Crit Care Med 1994, 149:1327-1334.

11. Tremblay LN, Slutsky AS: Ventilator-induced injury: from barotrauma to biotrauma. Proc Assoc Am Physicians 1998, 110:482-488.

12. Hernandez LA, Coker PJ, May S, Thompson AL, Parker JC: Mechanical ventilation increases microvascular permeability in oleic acid-injured lungs. J Appl Physiol 1990, 69:2057-2061.

13. Altemeier WA, Matute-Bello G, Frevert CW, Kawata Y, Kajikawa O, Martin TR, Glenny RW: Mechanical ventilation with moderate tidal volumes synergistically increases lung cytokine response to systemic endotoxin. Am J Physiol Lung Cell Mol Physiol 2004, 287:L533-L542.

14. Altemeier WA, Matute-Bello G, Gharib SA, Glenny RW, Martin TR, Liles WC: Modulation of lipopolysaccharide-induced gene transcription and promotion of lung injury by mechanical ventilation. J /mmuno/ 2005, 175:3369-3376.

15. Dhanireddy S, Altemeier WA, Matute-Bello G, O'Mahony DS, Glenny RW, Martin TR, Liles WC: Mechanical ventilation induces inflammation, lung injury and extra-pulmonary organ dysfunction in experimental pneumonia. Lab Invest 2006, 86:790-799.

16. Kawai T, Akira S: The role of pattern-recognition receptors in innate immunity: update on Toll-like receptors. Nat Immunol 2010, 11:373-384.

17. Jiang D, Liang J, Fan J, Yu S, Chen S, Luo Y, Prestwich GD, Mascarenhas MM, Garg HG, Quinn DA, Homer RJ, Goldstein DR, Bucala R, Lee PJ, Medzhitov R, Noble PW: Regulation of lung injury and repair by Toll-like receptors and hyaluronan. Nat Med 2005, 11:1173-1179.

18. Schaefer L, Babelova A, Kiss E, Hausser HJ, Baliova M, Krzyzankova M, Marsche G, Young MF, Mihalik D, Gotte M, Malle E, Schaefer RM, Grone HJ: The matrix component biglycan is proinflammatory and signals through Toll-like receptors 4 and 2 in macrophages. J Clin Invest 2005, 115:2223-2233.

19. Piccinini AM, Midwood KS: DAMPening inflammation by modulating TLR signalling. Mediators Inflamm 2010. [Epub ahead of print]

20. Joly AL, Wettstein G, Mignot G, Ghiringhelli F, Garrido C: Dual role of heat shock proteins as regulators of apoptosis and innate immunity. J Innate Immun 2010, 2:238-247.

21. Andersson $\mathrm{U}$, Tracey KJ: HMGB1 is a therapeutic target for sterile inflammation and infection. Annu Rev Immunol 2011, 29:139-162.

22. Foell D, Wittkowski H, VoglT, Roth J: $\mathrm{S} 100$ proteins expressed in phagocytes: a novel group of damage-associated molecular pattern molecules. J Leukoc Biol 2007, 81:28-37.

23. Vogl T, Tenbrock K, Ludwig S, Leukert N, Ehrhardt C, van Zoelen MA, Nacken W, Foell D, van der Poll T, Sorg C, Roth J: Mrp8 and Mrp14 are endogenous activators of Toll-like receptor 4, promoting lethal, endotoxin-induced shock. Nat Med 2007, 13:1042-1049.

24. Biragyn A, Ruffini PA, Leifer CA, Klyushnenkova E, Shakhov A, Chertov O, Shirakawa AK, Farber JM, Segal DM, Oppenheim JJ, Kwak LW: Toll-like receptor 4-dependent activation of dendritic cells by $\beta$-defensin 2 . Science 2002, 298:1025-1029.

25. Funderburg N, Lederman MM, Feng Z, Drage MG, Jadlowsky J, Harding CV Weinberg A, Sieg SF: Human defensin-3 activates professional antigen presenting cells via Toll-like receptors 1 and 2. Proc Natl Acad Sci U S A 2007, 104:18631-18635.

26. Karikó $\mathrm{K}, \mathrm{Ni} \mathrm{H}$, Capodici J, Lamphier M, Weissman D: mRNA is an endogenous ligand for Toll-like receptor 3. J Biol Chem 2004 , 279:12542-12550.

27. Vollmer J, Tluk S, Schmitz C, Hamm S, Jurk M, Forsbach A, Akira S, Kelly KM, Reeves WH, Bauer S, Krieg AM: Immune stimulation mediated by autoantigen binding sites within small nuclear RNAs involves Toll-like receptors 7 and 8. J Exp Med 2005, 202:1575-1585.

28. Zhang Q, Raoof M, Chen Y, Sumi Y, Sursal T, Junger W, Brohi K, Itagaki K, Hauser CJ: Circulating mitochondrial DAMPs cause inflammatory responses to injury. Nature 2010, 464:104-107.

29. Martinon F, Mayor A, Tschopp J: The inflammasomes: guardians of the body. Annu Rev Immunol 2009, 27:229-265.

30. Jin C, Flavell RA: Molecular mechanism of NLRP3 inflammasome activation. J Clin Immunol 2010, 30:628-631.

31. Bours MJ, Swennen EL, Di VF, Cronstein BN, Dagnelie PC: Adenosine 5 '-triphosphate and adenosine as endogenous signaling molecules in immunity and inflammation. Pharmacol Ther 2006, 112:358-404.

32. Mariathasan S, Weiss DS, Newton K, McBride J, O'Rourke K, Roose-Girma M, Lee WP, Weinrauch Y, Monack DM, Dixit VM: Cryopyrin activates the inflammasome in response to toxins and ATP. Nature 2006, 440:228-232. 
33. Martinon F: Mechanisms of uric acid crystal-mediated autoinflammation. Immunol Rev 2010, 233:218-232.

34. Babelova A, Moreth K, Tsalastra-Greul W, Zeng-Brouwers J, Eickelberg O, Young MF, Bruckner P, Pfeilschifter J, Schaefer RM, Gröne HJ, Schaefer L: Biglycan, a danger signal that activates the NLRP3 inflammasome via toll-like and P2X receptors. J Bio/ Chem 2009, 284:24035-24048.

35. Yamasaki K, Muto J, Taylor KR, Cogen AL, Audish D, Bertin J, Grant EP, Coyle AJ, Misaghi A, Hoffman HM, Gallo RL: NLRP3/cryopyrin is necessary for interleukin-1beta (IL-1 3 ) release in response to hyaluronan, an endogenous trigger of inflammation in response to injury. J Bio/ Chem 2009, 284:12762-12771.

36. van Zoelen MA, Achouiti A, van der Poll T: The role of the receptor for advanced glycation endproducts (RAGE) in infection. Crit Care 2011, $15: 208$

37. Uchida T, Shirasawa M, Ware LB, Kojima K, Hata Y, Makita K, Mednick G, Matthay ZA, Matthay MA: Receptor for advanced glycation end-products is a marker of type I cell injury in acute lung injury. Am J Respir Crit Care Med 2006, 173:1008-1015.

38. Hallgren R, Samuelsson T, Laurent TC, Modig J: Accumulation of hyaluronan (hyaluronic acid) in the lung in adult respiratory distress syndrome. Am Rev Respir Dis 1989, 139:682-687.

39. Mascarenhas MM, Day RM, Ochoa CD, Choi WI, Yu L, Ouyang B, Garg HG Hales CA, Quinn DA: Low molecular weight hyaluronan from stretched lung enhances interleukin-8 expression. Am J Respir Cell Mol Biol 2004, 30:51-60

40. Heise RL, Stober V, Cheluvaraju C, Hollingsworth JW, Garantziotis S: Mechanical stretch induces epithelial-mesenchymal transition in alveolar epithelia via hyaluronan activation of innate immunity. J Biol Chem 2011, 286:17435-17444.

41. Bai KJ, Spicer AP, Mascarenhas MM, Yu L, Ochoa CD, Garg HG, Quinn DA: The role of hyaluronan synthase 3 in ventilator-induced lung injury. Am J Respir Crit Care Med 2005, 172:92-98.

42. Mrabat H, Beagle J, Hang Z, Garg HG, Hales CA, Quinn DA: Inhibition of HA synthase 3 mRNA expression, with a phosphodiesterase 3 inhibitor, blocks lung injury in a septic ventilated rat model. Lung 2009, 187:233-239.

43. Liu YY, Lee CH, Dedaj R, Zhao H, Mrabat H, Sheidlin A, Syrkina O, Huang PM, Garg HG, Hales CA, Quinn DA: High-molecular-weight hyaluronan - a possible new treatment for sepsis-induced lung injury: a preclinical study in mechanically ventilated rats. Crit Care 2008, 12:R102.

44. Al-Jamal R, Ludwig MS: Changes in proteoglycans and lung tissue mechanics during excessive mechanical ventilation in rats. Am J Physiol Lung Cell Mol Physiol 2001, 281:1078-1087.

45. Kira S, Mori M, Takatani J, Uchino T, Yasuda N, Miyakawa H, Noguchi T: Effects of high peak airway pressure on the expression of heat shock protein 70 in rat lungs: a preliminary study. Acta Anaesthesio/ Scand 2006, 50:469-474.

46. Yoo CG, Lee S, Lee CT, Kim YW, Han SK, Shim YS: Anti-inflammatory effect of heat shock protein induction is related to stabilization of $I_{K B a}$ through preventing IKB kinase activation in respiratory epithelial cells. J /mmunol 2000, 164:5416-5423.

47. Ribeiro SP, Rhee K, Tremblay L, Veldhuizen R, Lewis JF, Slutsky AS: Heat stress attenuates ventilator-induced lung dysfunction in an ex vivo rat lung model. Am J Respir Crit Care Med 2001, 63:1451-1456.

48. DeMeester SL, Buchman TG, Cobb JP: The heat shock paradox: does NF-KB determine cell fate? FASEB J 2001, 15:270-274.

49. Ganter MT, Ware LB, Howard M, Roux J, Gartland B, Matthay MA, Fleshner M, Pittet JF: Extracellular heat shock protein 72 is a marker of the stress protein response in acute lung injury. Am J Physiol Lung Cell Mol Physiol 2006, 291:354-361.

50. Chase MA, Wheeler DS, Lierl KM, Hughes VS, Wong HR, Page K: Hsp72 induces inflammation and regulates cytokine production in airway epithelium through a TLR4- and NF-kB-dependent mechanism. J Immunol 2007, 179:6318-6324.

51. van Zoelen MA, Ishizaka A, Wolthuls EK, Choi G, van der Poll, Schultz MJ: Pulmonary levels of high-mobility group box 1 during mechanical ventilation and ventilator-associated pneumonia. Shock 2008, 29:441-445

52. Ogawa EN, Ishizaka A, Tasaka S, Koh H, Ueno H, Amaya F, Ebina M, Yamada S, Funakoshi Y, Soejima J, Moriyama K, Kotani T, Hashimoto S, Morisaki H, Abraham E, Takeda J: Contribution of high-mobility group box-1 to the development of ventilator-induced lung injury. Am J Respir Crit Care Med 2006, 174:400-407

53. Abraham E, Arcaroli J, Carmody A, Wang H, Tracey KJ: HMG-1 as a mediator of acute lung inflammation. J Immuno/ 2000, 165:2950-2954

54. Copland IB, Kavanagh BP, Engelberts D, McKerlie C, Belik J, Post M: Early changes in lung gene expression due to high tidal volume. Am J Respir Crit Care Med 2003, 168:1051-1059.

55. Wittkowski H, Sturrock A, van Zoelen MA, Viemann D, van der Poll T, Hoidal JR, Roth J, Foell D: Neutrophil-derived S100A12 in acute lung injury and respiratory distress syndrome. Crit Care Med 2007, 35:1369-1375.

56. Lorenz E, Muhlebach MS, Tessier PA, Alexis NE, Duncan HR, Seeds MC, Peden DB, Meredith W: Different expression ratio of S100A8/A9 and S100A12 in acute and chronic lung diseases. Respir Med 2008, 102:567-573.

57. Rich PB, Douillet CD, Mahler SA, Husain SA, Boucher RC: Adenosine triphosphate is released during injurious mechanical ventilation and contributes to lung edema. J Trauma 2003, 55:290-297.

58. Matsuyama H, Amaya F, Hashimoto S, Ueno H, Beppu S, Mizuta M, Shime N, Ishizaka A, Hashimoto S: Acute lung inflammation and ventilator-induced lung injury caused by ATP via the P2Y receptors: an experimental study. Respir Res 2008, 9:79.

59. Riteau N, Gasse P, Fauconnier L, Gombault A, Couegnat M, Fick L, Kanellopoulos J, Quesniaux VF, Marchand-Adam S, Crestani B, Ryffel B, Couillin I: Extracellular ATP is a danger signal activating P2X7 receptor in lung inflammation and fibrosis. Am J Respir Crit Care Med 2010, 182:774-783.

60. Kuipers M, Aslami H, Van der Poll T, Schultz M, Wieland C: Danger signal uric acid is involved in ventilator-induced lung injury pathogenesis [abstract]. Crit Care 2011, 15(Suppl 1):P192.

61. Gasse P, Riteau N, Charron S, Girre S, Fick L, Petrilli V, Tschopp J, Lagente V, QuesniauxVF, Ryffel B, Couillin I: Uric acid is a danger signal activating NALP3 inflammasome in lung injury inflammation and fibrosis. Am J Respir Crit Care Med 2009, 179:903-913

62. Vaneker M, Joosten LA, Heunks LM, Snijdelaar DG, Halbertsma FJ, van EJ, Netea MG, van der Hoeven JG, Scheffer GJ: Low-tidal-volume mechanical ventilation induces a toll-like receptor 4-dependent inflammatory response in healthy mice. Anesthesiology 2008, 109:465-472

63. Vaneker M, Heunks LM, Joosten LA, van Hees HW, Snijdelaar DG, Halbertsma FJ, van Egmond J, Netea MG, van der Hoeven JG, Scheffer GJ: Mechanical ventilation induces a Toll/interleukin-1 receptor domain containing adaptor inducing interferon beta-dependent inflammatory response in healthy mice. Anesthesiology 2009, 111:836-843.

64. Chun CD, Liles WC, Frevert CW, Glenny RW, Altemeier WA: Mechanical ventilation modulates Toll-like receptor-3-induced lung inflammation via a MyD88 dependent, TLR4 independent pathway: a controlled animal study. BMC Pulm Med 2010, 10:57.

65. Villar J, Cabrera NE, Casula M, Flores C, Valladares F, Diaz-Flores L, Muros M, Slutsky AS, Kacmarek RM: Mechanical ventilation modulates TLR4 and IRAK-3 in a non-infectious, ventilator-induced lung injury model. Respir Res 2010, 11:1-11.

66. Murray LA, Knight DA, McAlonan L, Argentieri R, Joshi A, Shaheen F, Cunningham M, Alexopolou L, Flavell RA, Sarisky RT, Hogaboam CM: Deleterious role of TLR3 during hyperoxia-induced acute lung injury. Am $J$ Respir Crit Care Med 2008, 178:1227-1237.

67. Villar J, Cabrera N, Casula M, Flores C, Valladares F, Muros M, Blanch L, Slutsky AS, Kacmarek RM: Mechanical ventilation modulates Toll-like receptor signaling pathway in a sepsis-induced lung injury model. Intensive Care Med 2010, 36:1049-1057.

68. Moriyama K, Ishizaka A, Nakamura M, Kubo H, Kotani T, Yamamoto S, Ogawa EN, Kajikawa O, Frevert CW, Kotake Y, Morisaki H, Koh H, Tasaka S, Martin TR, Takeda J: Enhancement of the endotoxin recognition pathway by ventilation with a large tidal volume in rabbits. Am J Physiol Lung Cell Mol Physiol 2004, 286:L1114-L1121.

69. Ranieri VM, Suter PM, Tortorella C, De TR, Dayer JM, Brienza A, Bruno F, Slutsky AS: Effect of mechanical ventilation on inflammatory mediators in patients with acute respiratory distress syndrome: a randomized controlled trial. JAMA 1999, 282:54-61.

70. Frank JA, Pittet JF, Wray C, Matthay MA: Protection from experimental ventilator-induced acute lung injury by IL-1 receptor blockade. Thorax 2008, 63:147-153

71. Zhang H, Tasaka S, Shiraishi Y, Fukunaga K, Yamada W, Seki H, Ogawa Y, Miyamoto K, Nakano Y, Hasegawa N, Miyasho T, Maruyama I, Ishizaka A: Role of soluble receptor for advanced glycation end products on endotoxininduced lung injury. Am J Respir Crit Care Med 2008, 178:356-362.

72. Englert JM, Hanford LE, Kaminski N, Tobolewski JM, Tan RJ, Fattman CL, Ramsgaard L, Richards TJ, Loutaev I, Nawroth PP, Kasper M, Bierhaus A, Oury 
TD: A role for the receptor for advanced glycation end products in idiopathic pulmonary fibrosis. Am J Pathol 2008, 172:583-591.

73. Reynolds PR, Schmidt RE, Kasteler SD, Sturrock A, Sanders K, Bierhaus A, Nawroth PP, Paine R 3rd, Hoidal JR: Receptors for advanced glycation endproducts targeting protects against hyperoxia-induced lung injury in mice. Am J Respir Cell Moll Biol 2010, 42:545-551.

74. He M, Kubo H, Ishizawa K, Hegab AE, Yamamoto Y, Yamamoto H, Yamaya M: Receptors for advanced glycation end-products in lung fibrosis. Am J Physiol Lung Cell Mol Physiol 2007, 293:L1427-L1436.

75. Barnay-Verdier S, Fattoum L, Borde C, Kaveri S, Gibot S, Maréchal V: Emergence of autoantibodies to HMGB1 is associated with survival in patients with septic shock. Intensive Care Med 2011, 37:957-962.
76. Tidswell M, Tillis W, Larosa SP, Lynn M, Wittek AE, Kao R, Wheeler J, Gogate J, Opal SM: Phase 2 trial of eritoran tetrasodium (E5564), a toll-like receptor 4 antagonist, in patients with severe sepsis. Crit Care Med 2010, 38:72-83.

\section{doi:10.1186/cc10437}

Cite this article as: Kuipers MT, et al.: Bench-to-bedside review:

Damage-associated molecular patterns in the onset of ventilator-induced lung injury. Critical Care 2011, 15:235. 